\title{
Checkpoint recovery in cells: how a molecular understanding can help in the fight against cancer René H. Medema ${ }^{1}$ and Libor Macůrek ${ }^{2 *}$
}

\author{
Addresses: ${ }^{1}$ Department of Medical Oncology, University Medical Center, Utrecht, the Netherlands; ${ }^{2}$ Department of Genome Integrity, \\ Institute of Molecular Genetics, Academy of Sciences of the Czech Republic, Prague, Czech Republic \\ *Corresponding author: Libor Macůrek (libor.macurek@img.cas.cz) \\ Fl000 Biology Reports 20II, 3:10 (doi:10.3410/B3-10) \\ This is an open-access article distributed under the terms of the Creative Commons Attribution-Non Commercial License \\ (http://creativecommons.org/licenses/by-nc/3.0/legalcode), which permits unrestricted use, distribution, and reproduction in any medium, \\ provided the original work is properly cited. You may not use this work for commercial purposes. \\ The electronic version of this article is the complete one and can be found at: http://f1000.com/reports/b/3/10
}

\begin{abstract}
Dysregulation of the cell cycle is the underlying mechanism of neoplasia. Healthy cells prevent propagation of DNA mutations to progeny by activation of cellular checkpoints, which allows time for DNA repair. On the other hand, activation of the DNA damage response is also the general principle of many current cancer treatments. Thus, recent advances in understanding how checkpoints in the cell cycle work at the molecular level open the door to new approaches to antitumor therapy.
\end{abstract}

\section{Introduction}

The cell cycle, in which cells replicate their genome and then physically divide into daughter cells, is an essential function in keeping multicellular organisms alive and healthy. However, various environmental factors (such as ionizing radiation or ultraviolet irradiation, and chemotherapy) as well as erroneous physiological processes (such as stalled replication forks or production of reactive oxygen species from metabolic reactions) cause undesired mutations that can lead to genomic instability and cancer. To prevent transfer of mutations to offspring, cells have evolved checkpoints that sense DNA damage and prevent progression through the cell cycle to allow DNA repair. Checkpoints are controlled by ATM (ataxia telangiectasia mutated) and ATR (ataxia telangiectasia and Rad3-related protein) kinases that activate their downstream effector kinases Chk2 (checkpoint kinase 2) and Chk1, respectively, and regulate multiple components of the cell cycle control and DNA repair pathways $[1,2]$. If the extent of DNA damage exceeds the capacity of repair mechanisms, cells are either permanently withdrawn from the cell cycle (senescence and/or quiescence) or are eliminated by programmed cell death (apoptosis). However, in most cases DNA lesions are successfully repaired and cells re-enter the cell cycle in a process called checkpoint recovery. Here we discuss recent advances in our understanding of checkpoint recovery and its relevance for human cancer.

\section{Recent advances}

Proliferating cells repeatedly pass through interphase (consisting of the G1, S, and G2 phases in which cells grow, replicate DNA, and duplicate centrosomes, respectively) followed by nuclear division (mitosis) and cellular division (cytokinesis). Transitions between the phases in the cell cycle are controlled by evolutionarily conserved cyclin-dependent kinases (CDKs), which act in complex with various cyclins, the principal regulators of the cell cycle. In the case of the G2/M transition, these components are represented by Cdk1/cyclin B. Interestingly, data from mice genetics indicate that Cdk1 is the only essential CDK, because proliferating cells can substitute for loss of any other CDK [3]. This indicates that the G2/M transition is carefully guarded, probably because an arrest in the G2 checkpoint is the last chance for the cell to prevent transmission of mutations to progeny. As untimely activation of Cdk1 can cause premature mitotic entry with deleterious consequences, activity of Cdk1 is carefully regulated at multiple levels (see Figure 1) [4]. 
Figure I. Model for G2/M transition and checkpoint recovery

G2
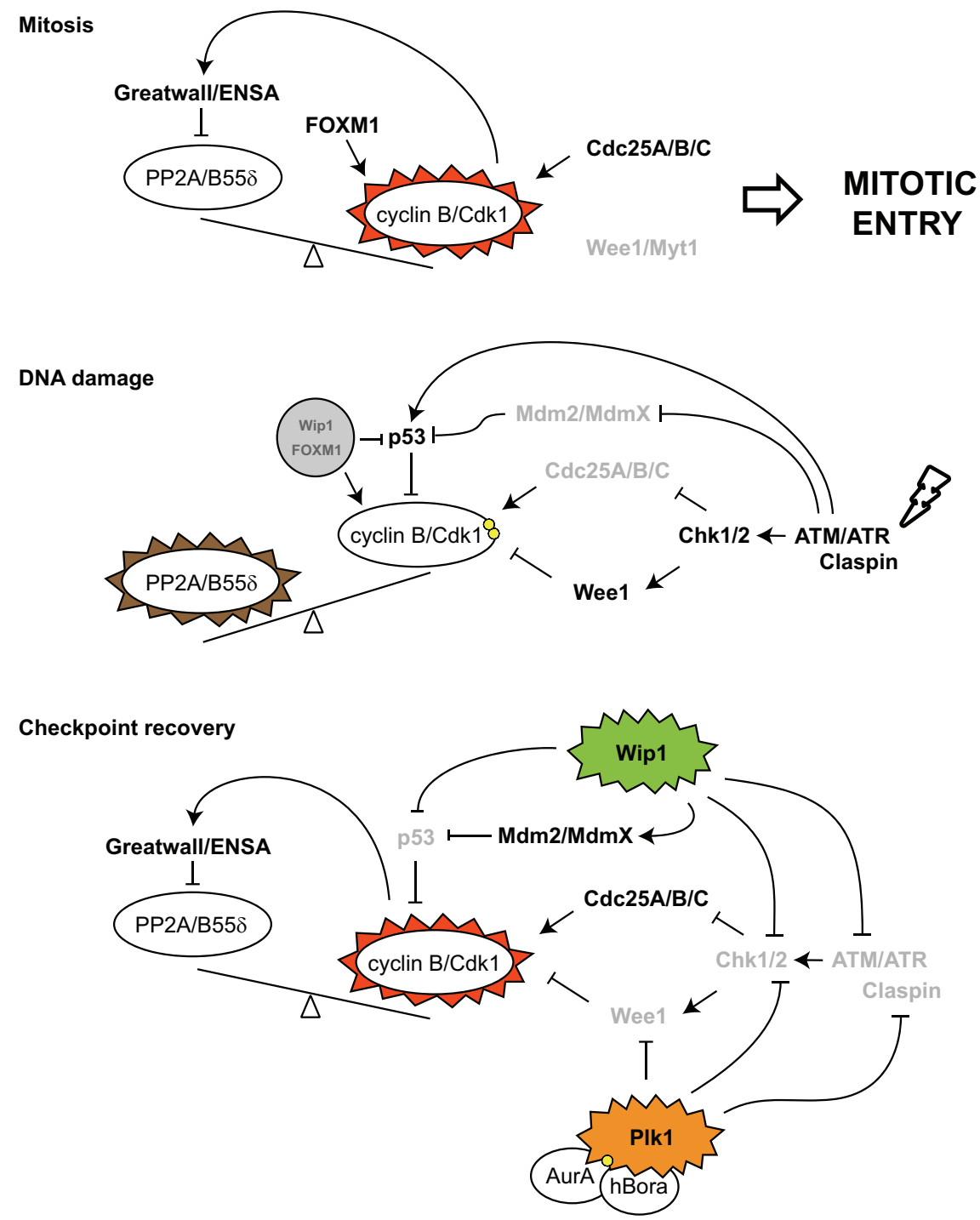

G2: The activity of PP2A outweighs the capacity of cyclin B/Cdkl to phosphorylate its substrates. Activity of cyclin B/Cdkl is very low due to inhibitory phosphorylation by Weel and Mytl (yellow circles). Mitosis: Expression of cyclin B is stimulated by FOXMI. Following dephosphorylation of CdkI by Cdc25A/B/C, cyclin B/Cdkl is activated. Through Greatwall, it inhibits PP2A, and by phosphorylation of multiple substrates, it initiates mitotic entry. DNA damage: The cell remains arrested at the $\mathrm{G} 2$ checkpoint and cyclin $\mathrm{B} / \mathrm{Cdkl}$ is kept in an inactive state by Weel and by transcriptional repression of cyclin $\mathrm{B}$ by p53. Basal activities of FOXMI and WipI (gray circle) prevent cyclin B levels from dropping below a threshold during the checkpoint. Checkpoint recovery: After successful DNA repair, the checkpoint is switched off by fully activated Wipl phosphatase and PlkI kinase, both contributing to activation of cyclin B/CdkI and enabling checkpoint recovery.

ATM, ataxia telangiectasia mutated; ATR, ataxia telangiectasia and Rad3-related protein; AurA, aurora kinase A; Cdc25A/B/C, cell division cycle 25A, B and C; CdkI, cyclin-dependent kinase I; ChkI/2, checkpoint kinase I and 2; ENSA, $\alpha$-endosulfine; FOXMI, forkhead box protein MI; hBora, human Bora; PlkI, Polo-like kinase I; PP2A, protein phosphatase 2A; Wipl, wild-type p53-induced phosphatase I. 
First, cyclin B levels are low in G1 and gradually increase in G2, just before cells need to activate Cdk1 to promote mitotic entry. Second, Wee1 and Myt1 kinases directly inhibit Cdk1 by phosphorylating its Thr-14 and Tyr-15 residues. Removal of these inhibitory modifications is controlled by members of the CDC25 (cell division cycle 25) family of phosphatases and leads to a rapid activation of Cdk1/cyclin B. Finally, an initial activation of Cdk1/ cyclin B stimulates the activity of Cdc25 and inactivates Wee1, creating two feedback loops that result in a switchlike activation of Cdk1. Activation of the DNA damage checkpoint in the G2 phase leads to increased activation of Wee1 as well as to degradation of Cdc25A [5], inhibition of Cdc25B [6], or cytosolic sequestration of Cdc25C [7,8], which all contribute to keeping Cdk1 activity low and preventing mitotic entry. During checkpoint recovery, cells rely on Plk1 (Polo-like kinase 1), which targets both Wee1 and Claspin (an essential cofactor of ATR) for proteasomal degradation [9-12]. Plk1 also promotes nuclear translocation of Cdc25C [13] and directly inhibits Chk2 and the p53 binding protein 53BP1 [14]. Interestingly, Plk1 activity is redundant in unperturbed mitotic entry whereas it becomes essential in checkpoint recovery, and this function is conserved in organisms ranging from yeast to humans. Activity of Plk1 is low after DNA damage whereas it becomes fully active during checkpoint recovery [15]. Phosphorylation within the T-loop of Plk1 is driven by Aurora-A kinase in complex with an adaptor protein, hBora, and is essential for activation of Plk1 and for checkpoint recovery [17]. Apart from its role in recovery, the yeast Plk1 homolog Cdc5 is indispensable for adaptation to irreparable DNA damage $[17,18]$; however, it remains unclear whether this pathway is conserved also in higher eukaryotes.

Although Plk1 activity is essential for recovery, it is not sufficient, indicating that additional control mechanisms exist. As DNA damage response pathways mostly rely on phosphorylation of multiple substrates, phosphatases that counteract such modifications are likely candidates to be involved in silencing the checkpoint and promoting checkpoint recovery. This was borne out in a study showing that two members of the protein phosphatase 2C (PP2C) family, Ptc2 and Ptc3, are necessary for checkpoint recovery in yeast [19]. In mammals, it was suggested that multiple phosphatases participate in inhibition of the DNA damage response pathway [20]. Among these, wild-type p53-induced phosphatase 1 (Wip1; also called PP2C-delta or PPM1D) seems to play a central role because it specifically recognizes a $\mathrm{p}(\mathrm{S} / \mathrm{T}) \mathrm{Q}$ motif, phosphorylated mostly by ATM/ATR kinases, allowing Wip1 to efficiently dephosphorylate multiple players in the DNA damage response pathway [21]. Although Wip1 dephosphorylates many targets, the most relevant for checkpoint recovery is probably the tumor suppressor p53 [22]. The presence of Wip1 throughout the checkpoint counteracts the function of p53 as a transcriptional repressor of mitotic inducers [22] and thus allows levels of cyclin B and Plk1 to be kept high enough for eventual checkpoint recovery following successful repair of damaged DNA [22]. Wip1 can regulate p53 by multiple mechanisms. Apart from a direct dephosphorylation of pSer15 on p53, Wip1 has been shown to decrease p53 levels by activating the ubiquitin E3 ligase $\mathrm{Mdm}$ 2, which targets p53 for proteasomal degradation, and also through activation of $\mathrm{MdmX}$, which directly inhibits transcriptional activity of p53 at promoters $[23,24]$. Determining which one of these mechanisms is the most physiologically relevant still remains unaccomplished; however, counteracting the p53 function seems to be the major role for Wip1. This view is further supported by finding high expression levels of Wip1 in tumors that do not have inactivating mutations in p53 [25]. Conversely, overexpression of Wip1 is very rare in tumors carrying mutations in p53, possibly because the selection pressure for amplification of the Wip1 locus was lost by inactivating p53.

Recent data indicate that driving the G2/M transition is more complex than previously anticipated. It appears that apart from mechanisms regulating Cdk1/cyclin B activity as described above, cells also actively control the outcome of Cdk1 activation at the level of its multiple substrates. This is achieved by PP2A-B55 $\delta$ phosphatase, which actively reverses phosphorylations made by $\mathrm{Cdk}$ during the interphase and thus prevents premature mitotic entry [26]. Strikingly, the activity of PP2A-B55 $\delta$ is inhibited by a Greatwall kinase (called MAST-L [microtubule-associated serine/threonine-protein kinase-like] in humans) that is active in mitosis and ensures that cells pass through mitosis with full phosphorylation of Cdk1 substrates [27-29]. Recently it has been demonstrated that this is achieved by phosphorylation of a PP2A inhibitor, Arpp19/Ensa (cAMP-regulated phosphoprotein 19/ $\alpha$-endosulfine), by Greatwall [30, 31]. Importantly, Greatwall is activated in mitosis through phosphorylation by Cdk1/cyclin B, and once phosphorylated, forms a negative feedback loop to PP2A [32]. In light of these new findings, one can think of the G2/M transition as a balance between Cdk1/ cyclin B activity and activity of the opposing PP2A phosphatase. In the normal cell cycle, Cdk1/cyclin B activity eventually outweighs that of PP2A and cells enter mitosis. Conversely, checkpoint mechanisms block the activation of Cdk1 which may push the balance towards activity of PP2A and prevent mitotic entry. This would imply that cells that repair DNA lesions and enter mitosis through a checkpoint recovery pathway need to 
overcome a higher barrier generated by PP2A than undamaged cells. This suggests that additional mechanisms (such as the activity of Plk1) are likely to be required for checkpoint recovery to support Cdk1 in the fight against the phosphatase-induced barrier. Moreover, prolonged arrest in the G2 checkpoint leads to activation of p53, which causes a drop in levels of cyclin B and Plk1 and further lowers the capacity of cells to recover. It appears that cells held at the G2 checkpoint adopt mechanisms (such as activating Wip1 to counteract the effect of p53) that prevent a drop of mitotic-inducing activity below a certain threshold and retain competence for eventual recovery. This model is further supported by a recent finding that cells need to maintain a basal level of Cdk activity during a DNA damage-induced G2 arrest in order to recover [33]. This enables cells to retain the transcriptional activity of the proliferation-promoting forkhead box protein FOXM1 throughout the DNA damage and allows them to sustain high levels of cyclin B [33]. How the basal activity of Cdk1 is regulated throughout the DNA damage, however, still remains to be elucidated. An attractive possibility is that Greatwall inhibition during the DNA damage response allows PP2A to reduce the phosphorylation level of some CDK substrates (leaving the basal Cdk1 activity untouched). Alternatively, PP2A might only target substrates of some CDKs, perhaps leaving substrates of Cdk2/cyclin A (including FOXM1) phosphorylated whereas acting preferentially on Cdk1 substrates. Clearly more research needs to be done to fully answer these issues.

\section{Future prospects}

Probably the most clinically relevant mode of DNA damage is represented by the genotoxic stress caused by radiotherapy or chemotherapy routinely used to cure cancer. Both strategies rely on induction of a cell death or permanent cell cycle arrest of tumor cells exposed to DNA damage, but at the same time they are limited by their toxic effects on normal tissues. With the recent major advances in understanding the molecular functioning of cell cycle checkpoints, it is hoped that in the future it may be possible to pharmacologically target components of the checkpoint recovery pathway, which may increase the sensitivity of tumor cells to current treatments.

\section{Abbreviations}

ATM, ataxia telangiectasia mutated; ATR, ataxia telangiectasia and Rad3-related protein; CDC25, cell division cycle 25; CDK, cyclin-dependent kinase; Chk2, checkpoint kinase 2; FOXM1, forkhead box protein M1; hBora, human Bora; Plk1, polo-like kinase 1; PP2C, protein phosphatase $2 \mathrm{C}$; $\mathrm{Thr}$, threonine; $\mathrm{Tyr}$, tyrosine; Wip1, wild-type p53-induced phosphatase 1.

\section{Competing interests}

The authors declare that they have no competing interests.

\section{Acknowledgments}

RHM was funded by the Netherlands Genomics Initiative of the Netherlands Organization for Scientific Research and LM was supported by the Grant Agency of the Czech Republic (P301/10/1525 and P305/10/ P420).

\section{References}

I. Jackson SP and Bartek J: The DNA-damage response in human biology and disease. Nature 2009, 46I:107I-8.

2. Bartek J and Lukas J: DNA damage checkpoints: from initiation to recovery or adaptation. Curr Opin Cell Biol 2007, 19:238-45.

3. Malumbres $M$ and Barbacid $M$ : Cell cycle, CDKs and cancer: a changing paradigm. Nat Rev Cancer 2009, 9:153-66.

4. Lindqvist $A$, Rodríguez-Bravo $\mathrm{V}$, Medema $\mathrm{RH}$ : The decision to enter mitosis: feedback and redundancy in the mitotic entry network. J Cell Biol 2009, I85:193-202.

5. Mailand N, Podtelejnikov AV, Groth A, Mann M, Bartek J, Lukas J: Regulation of $G(2) / M$ events by Cdc25A through phosphory lation-dependent modulation of its stability. EMBO J 2002, 2 I:59| I-20.

FI000 Factor 8

Evaluated by John Petrini 04 Dec 2002

6. Goldstone S, Pavey S, Forrest A, Sinnamon J, Gabrielli B: Cdc25dependent activation of cyclin A/cdk2 is blocked in $\mathbf{G} 2$ phase arrested cells independently of ATM/ATR. Oncogene 200I, 20:92I-32.

7. Peng CY, Graves PR, Thoma RS, Wu Z, Shaw AS, Piwnica-Worms H: Mitotic and G2 checkpoint control: regulation of 14-3-3 protein binding by phosphorylation of Cdc $25 \mathrm{C}$ on serine-2 I 6 . Science 1997, 277:150I-5.

8. Sanchez Y, Wong C, Thoma RS, Richman R, Wu Z, PiwnicaWorms H, Elledge S): Conservation of the Chkl checkpoint pathway in mammals: linkage of DNA damage to Cdk regulation through Cdc25. Science 1997, 277:|497-50I.

9. Mamely I, van Vugt MA, Smits VA, Semple JI, Lemmens B, Perrakis A, Medema RH, Freire R: Polo-like kinase-I controls proteasomedependent degradation of Claspin during checkpoint recovery. Curr Biol 2006, 16:1950-5.

10. Watanabe N, Arai H, Nishihara Y, Taniguchi M, Watanabe N, Hunter T, Osada H: M-phase kinases induce phospho-dependent ubiquitination of somatic Weel by SCFbeta-TrCP. Proc Natl Acad Sci U S A 2004, I 0 I:44 I 9-24.

FI000 Factor 8

Evaluated by Jonathon Pines 28 Apr 2004

II. Mailand N, Bekker-Jensen S, Bartek J, Lukas J: Destruction of Claspin by SCFbetaTrCP restrains Chkl activation and facilitates recovery from genotoxic stress. Mol Cell 2006, 23:307-18.

FI000 Factor 9

Evaluated by John Rouse 06 Sep 2006, Peter Jackson 09 Oct 2006

12. Peschiaroli A, Dorrello NV, Guardavaccaro D, Venere $M$, Halazonetis T, Sherman NE, Pagano M: SCFbetaTrCP-mediated degradation of Claspin regulates recovery from the DNA replication checkpoint response. Mol Cell 2006, 23:319-29.

FI000 Factor 7

Evaluated by Gennaro D’Urso 06 Sep 2006, Peter Jackson 09 Oct 2006 
13. Toyoshima-Morimoto F, Taniguchi E, Nishida E: PlkI promotes nuclear translocation of human Cdc25C during prophase. EMBO Rep 2002, 3:341-8.

\section{FI000 Factor 6}

Evaluated by Michael B Yaffe 08 Aug 2002

14. van Vugt MA, Gardino AK, Linding R, Ostheimer G], Reinhardt HC, Ong SE, Tan CS, Miao H, Keezer SM, Li J, Pawson T, Lewis TA, Carr SA, Smerdon SJ, Brummelkamp TR, Yaffe MB: A mitotic phosphorylation feedback network connects CdkI, PIkI, 53BPI, and Chk2 to inactivate the G(2)/M DNA damage checkpoint. PLoS Biol 2010, 8: I 000287.

15. Smits VA, Klompmaker R, Arnaud L, Rijksen G, Nigg EA, Medema RH: Polo-like kinase-I is a target of the DNA damage checkpoint. Nat Cell Biol 2000, 2:672-6.

16. Macůrek L, Lindqvist A, Lim D, Lampson MA, Klompmaker R, Freire R, Clouin C, Taylor SS, Yaffe MB, Medema RH: Polo-like kinase- $\mathrm{I}$ is activated by aurora $A$ to promote checkpoint recovery. Nature 2008, 455: I 19-23.

FI000 Factor 7

Evaluated by lain Hagan 13 Aug 2008, Jonathan Millar 09 Sep 2008

17. Toczyski DP, Galgoczy DJ, Hartwell LH: CDC5 and CKII control adaptation to the yeast DNA damage checkpoint. Cell 1997, 90:1097-106.

18. Vidanes GM, Sweeney FD, Galicia S, Cheung S, Doyle JP, Durocher D, Toczyski DP: CDC5 inhibits the hyperphosphorylation of the checkpoint kinase Rad53, leading to checkpoint adaptation. PLoS Biol 2010, 8: 1000286.

19. Leroy C, Lee SE, Vaze MB, Ochsenbien F, Guerois R, Haber JE, Marsolier-Kergoat MC: PP2C phosphatases Ptc2 and Ptc3 are required for DNA checkpoint inactivation after a doublestrand break. Mol Cell 2003, I I:827-35.

FI000 Factor 7

Evaluated by Orna Cohen-Fix 09 Apr 2003, Antony Carr 28 Apr 2003

20. Freeman A, Monteiro A: Phosphatases in the cellular response to DNA damage. Cell Commun Signal 2010, 8:27.

21. Lu $X$, Nguyen TA, Moon SH, Darlington $Y$, Sommer $M$, Donehower LA: The type 2C phosphatase WipI: an oncogenic regulator of tumor suppressor and DNA damage response pathways. Cancer Metastasis Rev 2008, 27:123-35.

22. Lindqvist A, de Bruijn M, Macurek L, Brás A, Mensinga A, Bruinsma W, Voets $O$, Kranenburg $O$, Medema RH: Wipl confers G2 checkpoint recovery competence by counteracting p53dependent transcriptional repression. EMBO J 2009, 28:3196-206.

23. Lu $X$, Nguyen TA, Moon SH, Darlington $Y$, Sommer $M$, Donehower LA: The type 2C phosphatase Wipl: an oncogenic regulator of tumor suppressor and DNA damage response pathways. Cancer Metastasis Rev 2008, 27:123-35.
24. Zhang $X$, Lin L, Guo H, Yang J, Jones SN, Jochemsen A, Lu X: Phosphorylation and degradation of $\mathrm{MdmX}$ is inhibited by Wipl phosphatase in the DNA damage response. Cancer Res 2009, 69:7960-8.

25. Bulavin DV, Demidov ON, Saito S, Kauraniemi P, Phillips C, Amundson SA, Ambrosino C, Sauter G, Nebreda AR, Anderson CW, Kallioniemi A, Fornace AJ Jr., Appella E: Amplification of PPMID in human tumors abrogates p53 tumorsuppressor activity. Nat Genet 2002, 31:210-5.

26. Mochida S, Ikeo S, Gannon J, Hunt T: Regulated activity of PP2A$B 55$ [delta] is crucial for controlling entry into and exit from mitosis in Xenopus egg extracts. EMBO J 2009, 28:2777-85.

27. Vigneron S, Brioudes E, Burgess A, Labbé JC, Lorca T, Castro A: Greatwall maintains mitosis through regulation of PP2A. EMBO J 2009, 28:2786-93.

FI000 Factor 8

Evaluated by Angel Nebreda 30 Oct 2009

28. Burgess A, Vigneron S, Brioudes E, Labbé JC, Lorca T, Castro A: Loss of human Greatwall results in $\mathbf{G} 2$ arrest and multiple mitotic defects due to deregulation of the cyclin B-Cdc2/PP2A balance. Proc Natl Acad Sci U S A 2010, 107:12564-9.

29. Voets $E$, Wolthuis RM: MASTL is the human orthologue of Greatwall kinase that facilitates mitotic entry, anaphase and cytokinesis. Cell Cycle 2010, 9:359I-60I.

30. Mochida S, Maslen SL, Skehel M, Hunt T: Greatwall phosphorylates an inhibitor of protein phosphatase 2A that is essential for mitosis. Science 2010, 330:1670-3.

FI000 Factor 16

Evaluated by Marie-Hélène Verlhac 07 Jan 20II, Angel Nebreda 20 Jan 20II, Brian Wadzinski 21 Mar 20II, Philipp Kaldis 05 Apr 201 I

31. Gharbi-Ayachi A, Labbé JC, Burgess A, Vigneron S, Strub JM, Brioudes E, Van-Dorsselaer A, Castro A, Lorca T: The substrate of Greatwall kinase, Arpp 19, controls mitosis by inhibiting protein phosphatase 2A. Science 2010, 330:1673-7.

FI000 Factor 14

Evaluated by Marie-Hélène Verlhac 07 Jan 20II, Angel Nebreda 19 Jan 2011, Philipp Kaldis 05 Apr 2011

32. Yu J, Zhao Y, Li Z, Galas S, Goldberg ML: Greatwall kinase participates in the cdc2 autoregulatory loop in Xenopus egg extracts. Mol Cell 2006, 22:83-9l.

FI000 Factor 7

Evaluated by Jonathon Pines 20 Apr 2006, lain Hagan 24 Apr 2006

33. Alvarez-Fernández M, Halim VA, Krenning L, Aprelia M, Mohammed S, Heck AJ, Medema RH: Recovery from a DNAdamage-induced $G_{2}$ arrest requires Cdk-dependent activation of FoxMI. EMBO Rep 2010, I I:452-8. 